Tugas Kelompok Perekonomian Indonesia Membuat Review Dari Artikel "THE DEVELOPMENT OF DIGITAL ECONOMY IN INDONESIA" By : Ahmad Zafrullah Tayibnapis and Lucia E. Wuryaningsih, Radita Gora

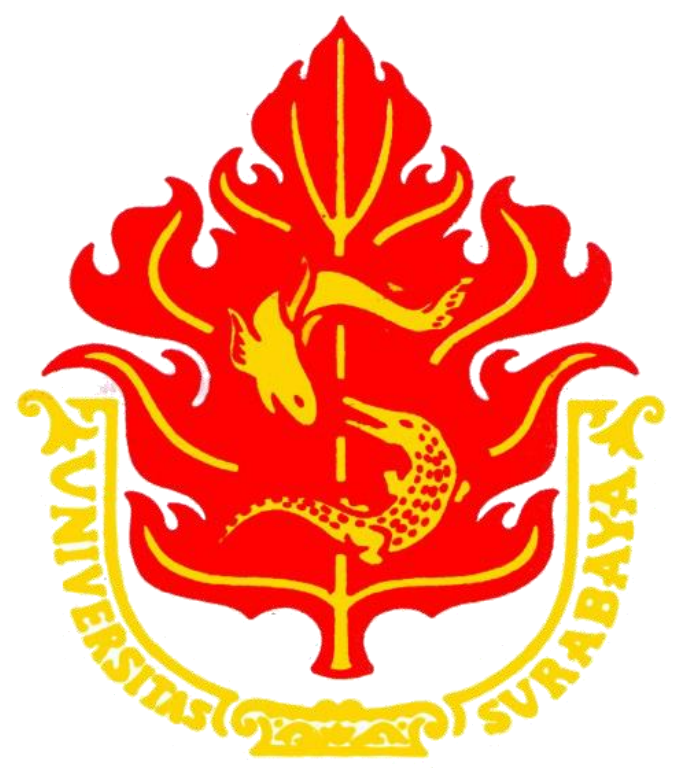

KP A

Kelompok 4

Di Review oleh:

Syahrul Munir Pahlevi (130217250)

Marcelino AdiSantoso (130118011)

Felix Pratama Bastian $\quad$ (130118101)

Fakultas Bisnis Dan Ekonomika

Universitas Surabaya 


\section{“THE DEVELOPMENT OF DIGITAL ECONOMY IN INDONESIA"}

- Abstrack

Dari Artikel diatas menjelaskan mengenai jumlah pengguna internet yang berada di Indonesia telah melampaui $50 \%$ dari total populasi yang berada di indonesia dengan pengeluaran rata-rata Rp6,5 juta per tahun untuk belanja online [CITATION Tay18 \l 1033]. Dari hal tersebut terjadi pengembangan dan perubahan gaya hidup digital dan industri berbasis teknologi digital telah menjadi kebutuhan bagi masyarakat, tetapi di sisi lain, itu akan menjadi "ancaman serius" bagi bisnis tradisional dan konvensional sebagai akibat dari perubahan karakteristik belanja konsumen, yaitu cepat, praktis, dan murah.

\section{- Introduction}

Saat ini dunia telah memasuki era industri 4.0 yang didasarkan pada teknologi baru dan mampu mengubah seluruh rantai dan manajemen di setiap cabang industry. Teknologi yang dampaknya berkembang pesat di Indonesia, ditandai dengan munculnya perusahaan startup, seperti sistem pembayaran dan layanan transfer uang, tabungan dan pinjaman, asuransi, penyedia layanan informasi keuangan, pasar modal, crowdfunding, dan manajemen kekayaan. Hal ini menyebabkan masyarakat Indonesia mengalami perubahan cepat ke arah teknologi dan menunjukkan bahwa teknologi mampu memainkan peran strategis dalam memberikan kemudahan dalam mengakses layanan keuangan yang ada. Dan mendapat respon positif dari masyarakat Indonesia karena sesuai dengan perilaku konsumen yang menginginkan layanan tanpa berada langsung di Bank, kantor maupun perusahaan keuangan.

Saat ini, layanan keuangan di perbankan digital telah berkembang dengan baik, seperti internet banking, mobile banking, AMS banking, ATM, e-money, phone-banking, galeri pembayaran, branchless banking, debit online, outlet digital, kartu kredit virtual, sistem manajemen kas, EDC, cabang seluler, akun seluler, dan aplikasi keuangan berbasis smartphone. Dengan semakin banyaknya pilihan produk dalam perbankan digital ini tentunya dengan maksud untuk memotivasi pelanggan agar lebih loyal dan menjadi bagian dari gaya hidup modern. Singapura, Jepang, dan Inggris adalah tiga negara pusat keuangan internasional yang telah dapat membuktikan dampak signifikan teknologi keuangan terhadap pertumbuhan ekonomi dan stabilitas sistem keuangan. Namun, terlepas dari hal-hal yang dikaitkan diatas industri jasa keuangan tersebut juga salah satu sektor yang paling rentan dalam kejahatan salah satunya berasal dari dunia maya (cybercrime). 


\section{- Literature Review}

Pada dasarnya sistem keuangan mempunyai peranan penting di dalam ekonomi Indonesia, khususnya dalam menyediakan fasilitas jasa keuangan yang secara kelembangaan di bagi menjadi 2 bagian besar, yaitu lembaga penyimpanan uang dan lembaga non penyimpangan uang. Permintaan uang telah berkembang dengan kehadiran ide William J.Baumol (1952) and James Tobin (1956) di mana teori tersebut mengukapkan suku bunga dan biaya perantara mempengaruhi permintaan uang untuk keperluan transaksi. Perkembangan teknologi akan penyebabkan turunnya rata-rata jumlah uang tunai yang di pegang oleh individu

\section{- Research Methodology}

Berdasarkan survey kualitatif yang dilakukan Ahmad Zafrullah Tayibnapis, Lucia E. Wuryaningsih, dan Gora untuk mencari tahu fenomena yang terjadi dengan menggunakan data primer pengguna internet sebanyak 100 responden dan sekunder data berasal dari berbagai sumber yang suda dipertanggungjawabkan. perkembangan teknologi dan permintaan konsumen di Indonesia menujukkan bahwa teknologi digitalpun terbukti mampu menyediakan barang dan jasa secara lebih nyaman, praktis, lebih murah, lebih cepat. Banyaknya produk digital berbasis jasa keuangan juga sangat diminati oleh masyarakat baik individu, pelaku bisnis dan juga UMKM. Di masa yang akan datang, ekonomi berbasis digital pun diharapkan akan menjadi salah satu pendorong ekonomi pertumbuhan dan pendapatan perkapita Indonesia saat lemahnya ekonomi global karena perang perdagangan dan peningkatan harga minyak di pasar internasional.

\section{- Finding and Discussion}

Berkembangnya teknologi kini sangat berperan pada aktivitas perekonomian di seluruh dunia karena juga memunculkan teknologi digital dengan menggunakan internet yang dapat mempermudah transaksi secara online. E-money adalah contoh dari berkembangnya alat pembayaran elektronik yang dimulai dengan memakai kartu ATM dan kartu kredit dan banyak digunakan oleh orang-orang. E-money telah berkembang pesat sejak tahun 2008 karena lebih simpel dan aman, pemerintah juga menyediakan ATM untuk mempermudah mengisi ulang uang elektronik dengan ini pengguna tidak perlu takut untuk kehabisan uang elektronik. Maka dari itu setiap bank memiliki lebih dari satu keuangan digital dan beupaya untuk menawarkan produk keuangan digital yang inovatif dan lebih maju. Contoh pembayaran elektronik yang lagi banyak dipakai masyarakat saat ini adalah OVO salah satu E-money terbaik di Indonesia. Dengan adanya OVO ini kita tidak perlu repot-repot 
membawa dompet, kita hanya perlu membawa Smartphone untuk topup apabila saldo OVO habis melalui m-banking. Dan kenyataannya semua penjual di mall pun menyediakan alat pembayaran elektronik, selain itu ojek online pun juga sama memakai OVO. Selain memudahkan transaksi OVO juga memberikan banyak promo untuk menarik pengguna OVO.

\section{MSMEs in DIGITAL ECONOMY ERA}

Sebelum internet berkembang, para pembisnis melakukan aktivitas jual beli secara tradisional dengan cara membuka toko dan konsumen dapat langsung melihat barang yang dijual secara langsung. Namun hal ini dapat memperlambat aktivitas jual beli karena sulit untuk mengiklankan barang yang dijual. Dengan adanya internet pola perilaku pembisnis mulai berubah, yaitu dapat membuka bisnis secara online yang dapat diiklankan secara global, dan konsumen tidak perlu repot-repot datang ke toko untuk membeli, konsumen hanya perlu melihat barang yang diinginkan lalu bayar melalui alat pembayaran elektronik dan penjual mengirim barang yang telah dibeli kepada alamat yang dituju. Kini semua mudah melalui teknologi digital yang telah berkembang

\section{- Concluding Remarks}

Perekonomian berbasis digital telah membuktikan peranan yang sangat strategis dalam mennyediakan barang dan jasa yang lebih praktis, murah dan cepat. Ketersediaan dari produk perbankan atau non perbankan dan jasa menggunakan teknologi digital sangat di apresiasi oleh komunitas. Perekonomian digital akan menjadi salah satu pendorong pertumbuhan dan pendapatan per kapita di pertengahan perang dagang ini. 


\section{References}

[1] Chariri, Anis.,'Landasan Filsafat dan Metode Penelitian Kualitatif. Makalah. Workshop Metodologi Penelitian Kuantitatif dan Kualitatif “. Fakultas Ekonomi Universitas Diponegoro. Semarang, 2009.

[2] Jelassi, Taufk, Albrecht Endes,"Strategies for e-business: Creating Value Through Electronic and Mobile Commerce: Concepts and Cases", $2^{\text {nd }}$ edition. United States of America: Prentice Hall, 2008.

[3] Nopirin. Ekonomi Moneter,'Edisi Keempat. Cetakan Ketujuh. Yogjakarta: BPFE, 2000.

[4] Tayibnapis, A. Z., Wuryaningsih, L. E., \& Gora, R. (2018). The Development of Digital Economy in Indonesia. IJMBS International Journal of Management and Business Studies, 8(3), 14-18.

[5] Tulman, Michael M.,"E-Business and E-Commerce for Managers", United States of America: Prentice Hall, 2001.

\section{Alamat DOI : 10.31227/osf.io/326bv}

